\title{
ON RETARDED NONLINEAR INTEGRAL INEQUALITIES OF GRONWALL AND APPLICATIONS
}

\author{
A. Abdeldaim, A. A. El-Deeb and Reda Gamal Ahmed
}

Abstract. By some new analysis techniques, we generalize the results presented by Pachpatte in [8] to nonlinear retarded inequalities, and also investigate some new forms. Some examples are presented to illustrate our results at the end.

Mathematics subject classification (2010): 26D10, 26D15, 26D20, 34A12, 34A40.

Keywords and phrases: Integral inequality, analysis technique, estimation, retarded integral and differential equation.

\section{REFERENCES}

[1] B. G. PAChPATte, Integral and finite difference inequalities and applications, Elsevier, 2006.

[2] L. OU-IANG, The boundedness of solutions of linear differential equations $y^{\prime \prime}+A(t) y=0$, Shuxue Jinzhan 3 (1957), 409-415.

[3] B. G. PACHPATTE, On some new inequalities related to certain inequalities in the theory of differential equations, Math. Anal. Appl. 189 (1995), 128-144.

[4] GRONWALL, Note on the derivatives with respect to a parameter of the solutions of a system of differential equations, Ann. Math. 20 (1919), 292-296, http://dx .doi .org/10. 2307/1967124.

[5] R. Bellman, The stability of solutions of linear differential equations, Duke. Math. 10 (1943), 643647, http://dx.doi.org/10.1215/S0012-7094-43-01059-2.

[6] O. Lipovan, A retarded Gronwall-like inequality and its applications, J. Math. Anal. Appl. 252 (2000), 389-401, http://dx.doi.org/10.1006/jmaa.2000.7085.

[7] WS. WANG, RC. LUO AND Z. LI, A new nonlinear retarded integral inequality and its application, J. Ineq. Appl. 2010:462163 8 (2010).

[8] B. G. PACHPATTE, On some new inequalities retarde to a certain inequality arising in the theory of differential equations, J. Math. Anal. Appl. 2000251 (2000), 736-751.

[9] D. S. Mitrinović, Analytic Inequalities, Springer-Verlag, Berlin/New York, 1970.

[10] F. William Ames And B. G. PACHPATte, Inequalities for Differential and Integral Equation, volume 197. Academic press (1998).

[11] BAHARI, A generalization of lemma of Bellman and its application to uniqueness problem of differential equation, Acta. Math. Acad. Sc. Hung 7 (1956), 81-94.

[12] P. AgARWAL, S. DENG AND W. ZHANG, Generalization of a retarded Gronwall-Like inequality and its application, Appl. Math. Comput. 165 (2005), 599-612.

[13] Hassan Mostafa El-Owaidy, Abdelwahab Abbas Ragab, Waleed Mostafa Kamal ABUElela AND AHMED ABDEL-MoneIM EL-DEEB, On some new nonlinear integral inequalities of Gronwall -Bellman type, Kyungpook Math 54 (2014), 555-575.

[14] A. ABDELDAim AND A. A. EL-DEEB, On some generalizations of certain retarded nonlinear integral inequalities with iterated integrals and an application in retarded differential equation,J. Egy. Math. Soc. 23(3)(2015), 470-475.

[15] H. El-Owaidy, A. Abdeldaim And A. A. El-Deeb, On Some New Retarded Nonlinear Integral Inequalities and Their Applications, Math. Sci. Lett. 3(2014), 157-164.

[16] A. Abdeldaim And A. A. El-DeEb, On Some New Nonlinear Retarded Inte-gral Inequalities with Iterated Integrals and their Applications in Integro-differential Equations, Bri. J. Math. \& Comput. Sc. 5(4) (2015), 479-491. 
[17] G. I. Chandirov, On a generalization of Gronwall's inequality and its applications, Uchen. Zap. Azerb. Univ. Ser. Fiz. Mat. Nauk, In Russian 6 (1956), 3-11.

[18] SAmIR SAKer, Odcillation Theory of Delay Differential and Difference Equations, VDM Verlag Dr. Müller Akteingesellschaft. Co. KG., 2010.

[19] A. ABDELDAIM AND A. A. EL-DEEB, On generalized of certain retarded nonlinear integral inequalities and its applications in retarded integro-differential equations, Appl. Math. Comput. 256 (2015), 375-380.

[20] A. A. El-Deeb And Reda Gamal Ahmed, On Some Explicit Bounds on Certain Retarded Nonlinear Integral Inequalities With Application, Adv. Inequ. Appl. 2016 Article-ID15 (2016), 19 pages.

[21] A. A. El-Deeb And Reda Gamal Ahmed, On Some Generalizations of Certain Nonlinear Retarded Integral Inequalities for Volterra-Fredholm Integral Equations and Their Applications in Delay Differential Equations, J. Egy. Math. Soc. 25 (2017) 279-285. 